\title{
The Trouble with TEK
}

\author{
OPENӘACCESS \\ DOI 10.14237/ebl.8.1.2017.1006
}

Copyright (C) 2017 by the author(s); licensee Society of Ethnobiology. This is an open-access article distributed under the terms of the Creative Commons Attribution-NonCommercial 4.0 International Public License (https://creativecommons.org/licenses/by-nc/4.0), which permits non-commercial use, distribution, and reproduction in any medium, provided the original author and source are credited.

I grew up in southern California loving to gather and consume WEPs, though they were a minority report in my family's TFS. I might even venture to say that my experience as a posttoddler seeking out what we called Indian chewing-gum, sour grass, soap root, and prickly pears sparked my enduring interest in TEK, LEK, IK, TREM, and the FEW nexus, inspiring both a personal and scholarly process of unearthing the CMP in which my own life unfolds, studying with and learning from IPs mainly in North, South and Mesoamerica.

\section{Great, right?}

To keep the trouble with 'TEK' simple and selfevident, I will limit myself here to voicing two core objections to acronym creep in general, and for ethnobiology in particular. First, acronyms nominalize processes. Secondly, the abundant use of acronyms obscures communication and, as a shibboleth, limits readership.

My most throat-tightening grievance regarding TEK is the way that term takes hostage the living, changing, evanescent, and emergent processes it pretends to describe as an abbreviation of 'Traditional Ecological Knowledge.' The word traditional is derived from the action "of handing over... of transmitting an idea, concept or teaching" (OED 2016). The word has its critics but that is for another debate another time (e.g., see Mallon 2010). Ecological knowledge is a "condition of knowing something" (OED 2016) about the interrelationships between living entities and their environments. The phenomenological experience of traditional ecological knowing is inescapably relational and transactional, best characterized by the way it activates or mediates interaction. First Nations and Indigenous scholars have attempted to correct the ways settler/colonial academics try to turn these active, living relations of knowing and acting into simple data points that can be compared and integrated with traditional Western modes of knowing (Mika 2012; Reo 2011; Smith et al. 2016). Somehow, by using a neat label and a gerund, it is easier to objectify people, other animals, plants, landscapes, a multitude of environments, and transform sources of life into 'resources' to be managed (Looking Horse 2016; Nadasdy 2003; Wyndham 2009).

Thus, the coagulation that is the phrase Traditional Ecological Knowledge itself is an epistemic shortcut that allows for the oversimplified objectification of complex and varied processes. It cuts networks of relatedness and sheds context. But, as the use of the additional shortcut of its acronym form grows more popular and spawns a hundred offspring (WEP, TFS, IK, LEK, etc., see above), we could surely agree that by not even bothering to spell out the words traditional, ecological, and knowledge, writing or uttering TEK instead, we lose all hope of remembering that we are communicating about living breathing relations.

By using TEK we are confessing to having chopped away the capillaries of connection and to be ok with placing our cauterized notions neatly in a box, tied and labeled as commodities. We tourniquet verbs into nouns. They are so much easier to sell that way. They can be sorted and stacked in piles and sold to conservationists, to policy planners, to government officials, even back to the people with whom they originated. The deep histories, the political realities, and the social inequities that likely adhere to the matter at hand can all thus be glossed over, elided, and seemingly depoliticized (Nadasdy 1999).

I remember that in my first year as a graduate student, I was shocked at how prevalent the use of acronyms and abbreviations was in the anthropology literature we read (predominantly those published after, say, 1980)-thus I was introduced to ABM, STS, ANT, and, yes, TEK. Some journals in the technical sciences have been so strict about word count that authors embraced acronyms to save those six, seven, or eight words in their total editorial count. People like to use field terms as a shortcut to a cloud of inter-related meanings. And these are shibboleths: 
they help create social in-group exclusivity, as do jargon or arcane vocabulary. In fact, I remember a first prick of self-satisfaction, of feeling part of an ingroup when I knew what TEK stood for, and another student did not. (I humbly apologize to whomever that was!) That is not the way to create the next generations of scholars who can write clearly about complex ecological interrelationships. Let's agree to give up our (delusional) aspiration of showing that we know the passwords to some elite clique and just write out what we are trying to say. Deep in the crust of our hearts we already know that there are no real kudos to be accumulated in the prestige-economy that is academia by taking these cognitive shortcuts.

Finally, the creep of the acronym is a warning symptom of a more pervasive militarization of daily life, including the daily life of academia. The US Military uses over 600 acronyms and abbreviations in its internal and external communications (Wikipedia 2016), explained by a justifiable need for quick, clear communications in the heat of battle, and in-group knowledge that contributes to linguistic and identity cohesion. For non-initiates, acronym-talk presents obstacles to understanding military commands or communiqués. Academia has innocently adopted many military innovations (the hand-me-downs of computers, email, GPS, drones, cargo pants, to name a few). But gentle reader, let us not mix up the IEDs with the OEDs. And if you are anything like me, when you are half way through an article you may no longer remember what the lonely letters of an acronym stand for. You find that you must search back through the piece to locate where the author first introduced the term. Don't let journal editors tell you that you must abbreviate for them to save a few tens of character spaces in layout. When you want to write or say TEK, instead try for words that really get to the heart of the matter. Your readers will notice and thank you.

So, let's keep the trouble with TEK in mind, and all live HEA. ${ }^{1}$

\section{Notes}

1. Authors working in the Romance genre will know this common, infelicitous acronym for Happily Ever After. The other acronyms above were gleaned from published articles I have encountered recently, and stand for, in alphabetical order:

ANT Actor-Network Theory

ABM Agent-Based Modeling
CMP Colonial Matrix of Power

FEW Food-Energy-Water nexus

GPS Global Positioning System

IED Improvised Explosive Device

IK Indigenous Knowledge

IPs Indigenous Peoples

LEK Local Ecological Knowledge

OED Oxford English Dictionary

STS Science \& Technology Studies

TEK Traditional Ecological Knowledge

TFS Traditional Food Systems

TREM Traditional Resource Ecosystem Management WEP Wild Edible Plant

Fortunately, Ethnobiology Letters and the Journal of Ethnobiology discourage acronyms, so we are usually in good company without them on these pages.

\section{References Cited}

Looking Horse, A. 2016. Important Message From Keeper of the Sacred White Buffalo Calf Pipe. Indian Country Media Network. 26 August. Available at: www.indiancountrymedianetwork.com. Accessed on December 10, 2016.

Mallon, S. 2010. Against Tradition. The Contemporary Pacific 22(2):362-381.

Mika, C. T. H. 2012. Overcoming 'Being' in Favour of Knowledge: The Fixing Effect of 'Mātauranga'. Educational Philosophy and Theory 44(10):1080-1092. DOI: 10.1111/j.1469-5812.2011.00771.x.

Nadasdy, P. 1999. The Politics of TEK: Power and the "Integration" of Knowledge. Arctic Anthropology 36(1-2):1-18.

Nadasdy, P. 2003. Hunters and Bureaucrats: Power, Knowledge, and Aboriginal-State Relations in the Southwest Yukon. Vancouver, University of British Columbia Press.

OED (Oxford English Dictionary). 2016. "Traditional" and "Knowledge" entries. Available at: www.oed.com. Accessed on October 2, 2016.

Reo, N. J. 2011. The Importance of Belief Systems in Traditional Ecological Knowledge Initiatives. The International Indigenous Policy Journal 2(4). Available at: http://ir.lib.uwo.ca/iipj/vol2/iss4/8. Accessed on November 15, 2016.

Smith, L. T., T. K. Maxwell, H. Puke, P. Temara. 2016. Indigenous Knowledge, Methodology and 
Mayhem: What is the Role of Methodology in Producing Indigenous Insights? A discussion from Mātauranga Māori. Knowledge Cultures 4(3):131-156.

Wikipedia. 2016. List of U.S. Government and Military Acronyms. Available at: https:// en.wikipedia.org/wiki/

June 3, 2017

Felice $S$. Wyndham

290 Stanton Way, Athens, GA, USA.

fwyndham@ethnobiologyletters.org
List_of_U.S._government_and_military_acronyms. Accessed September 13, 2016.

Wyndham, F. S. 2009. Spheres of Relation, Lines of Interaction: Subtle Ecologies of the Rarámuri Landscape in Northern Mexico. Journal of Ethnobiology 29(2):271-295. 